\title{
Robo-Advisors to Predict Switching of Jobs using Space in Handwriting Image
}

\author{
Sudiksha Chakraborty, Jyoti Majumder
}

\begin{abstract}
Predicting switching of jobs has been in quest for several years. The study starts with collection of manually written text specimen in A4 sheet. At the beginning gray scale or color copy is extracted by the robo-advisor and more shielding executed to transform to binary image. For identifying the gaps amidst characters Skew-normalization is used in the manuscript after segmentation. After that a comparison is computed with space mean among closed loops created by characters and word spaces to identify character. The characters are then matched with the requirements of job. Accordingly, the new appraisal is compared against the already existing. If the performance degrades, switching is predicted along with the possible job options. The main agenda of the document is to analyze switching jobs on the basis of behavior from gaps in manually written manuscripts. The recommended approach is approved with 600 samples of IAM database with diverse authors having various culture. The analysis concludes the recommended method attains $64 \%$ and above level of efficiency.
\end{abstract}

Keywords : Space Analysis; Character Analysis; Business Requirements; Performance Analysis; Switching of Jobs.

\section{INTRODUCTION}

During the last few years, predicting switching of jobs has been a topic of extreme demand and exploration. It can be done based on characteristics or behavior of an individual. The initial phase is dedicated towards understanding the core concepts across various areas of business. In the latter part, an individual can choose the job that best suits him/her. There may be numerous factors that influence the decision regarding the choice of job. Depending upon the priority, the individual may choose the field as per the market demand, interest area, job profiles and the compensation packages offered by the companies. But prior to that the most important basis should be the parity of the skills required for a particular field with the characteristics or behaviour of the person. The parity may be judged by his/her performance analysis- a way of which is the appraisal. If the appraisal degrades, he is not able to deliver his job properly and this indicates a switch in the field. Here it is expected that in recommended course of action, the manuscript given as input to the robo-advisor may only consist of skew [3], [10], [7], [13], [14] that can exist as a result of someone's mental perspective at that scenario. In the instance of exact positioning of the manuscript, lines in handwritten notes may however comprise of different types of slanting $[3],[10],[7],[13],[14]$ due to diversification in situations of

Revised Manuscript Received on September 10, 2019.

Sudiksha Chakraborty*, Dept. of Finance, IBS Kolkata, Kolkata, West Bengal, India.

(Email: sudiksha.chakraborty18@ibsindia,org)

Jyoti Majumder, Dept. of Marketing, IBS Kolkata, Kolkata, West Bengal, India.

(Email: jyoti.majumder18@ibsindia.org) writing. Thus, when implemented, the experimental values of normalized lines had more accuracy.

Next step being segmentation[9],[12] which convert the paired sample image into numerous clusters on the basis of background. The techniques used are K-mean segmentation [3],[6] and projection profile [3]. Now, last step is classification [7] method which is the essential section of the character analysis method. The paper concentrates on predicting switching of jobs by the robo-advisor through space calculation which is understanding and analyzing the character on the basis of comparison between word space and that of closed looped characters. Accordingly, the matching of those behaviors with the required skills for a particular job profile are done. Their performance in the current job are compared against the historical data and switching prediction is done if required.

Skew is technically defined as the distortion from a true value of symmetrical form. It is more developed to one sided direction. However, while handwriting analysis is being performed, the document needs to be independent of skew for accurate classification. It is required for to bring all the characters in a line to the same baseline for exact segmentation. Skew can be mainly classified into four typesNegative or Upward rising skew, Positive or Downward sloping skew, Normal or beeline skew and Wavy skew as in Fig. 1.

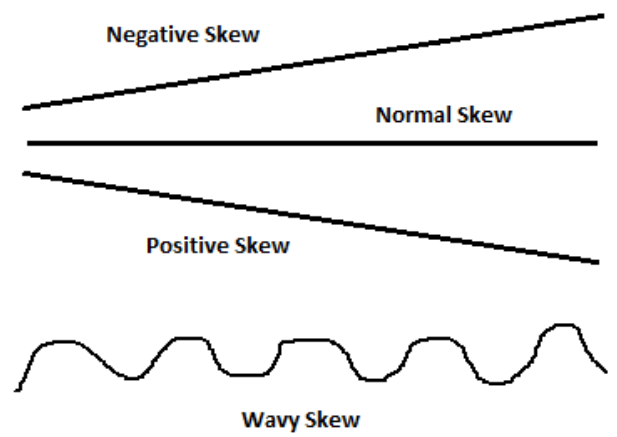

Fig 1. Orientation of Skew

Samples of skew in words including positive and negative orientation are as in Fig. 2.

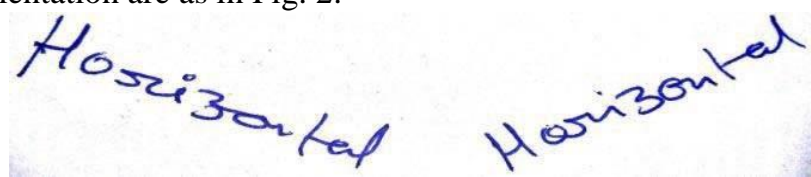

Fig 2: Positively skewed word and Negatively skew word 
When a document or note is considered for analysis, it is expected to have a skew angle in it. On performing segmentation of lines, it is often found that the beveled lines are having so much skew angles that lines are getting wiped off from either the above part or the part below. The result of which being the deviation in space calculations. Thus skew normalization is necessary to be applied.

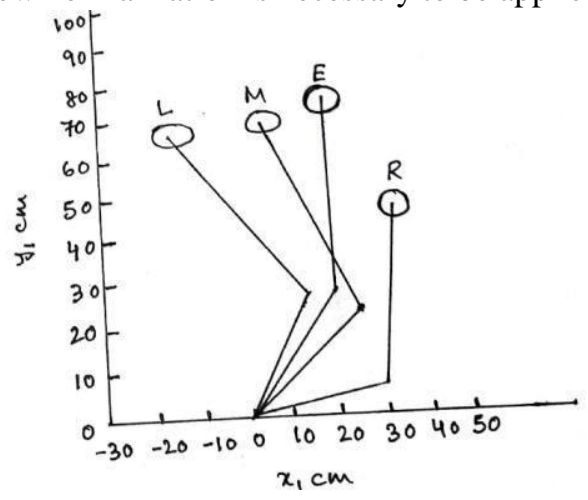

Fig 3. Letters having closed loops

In the above Fig. 3, inner circled characters in a handwritten document are shown. Anywhere words similar to "and", "gap", "boy", are seen, according to recommended work, inner loops of "a", "d", "g" and others are detected and radii of loops of all those letters are calculated and stored in a batch. [9] Summation of all the diameters of those similar letters is found out and then the mean of diameter is matched against mean word space in the image. Mathematically, when twice the mean of diameter of loops is more than the average of space in between words, the person is found to be conventional, if less, then the person is open-minded and if equal, the person is balanced and possesses some pre-defined qualities in previous papers. [9]

Robo-advisors, instead of following the traditional way of analyzing a questionnaire as input,[19] has analyzed a scanned handwriting sample taken as input. After performing the above mentioned algorithms, it will analyze the current appraisal with the previous one. In case of degradation, it will predict a switch option. It first finds the matching job profiles and then eliminates the ones similar to the job the individual is working in currently through predictive analytics by using artificial intelligence.[20]

\section{LITERATURE REVIEW}

In 2008, M Sarfraj and Z Rasheed [3] came up with visualization techniques for understanding and implementing projection profiles.

In 2010, Champa H N, K R Ananda Kumar [7] talked about human behavior through character classification focusing mainly on traits for job profiles.

In 1992, G. Story, L. O 'eorman, D. Fox, L. Schaper and H. Jagadish [13] clearly stated that in handwriting analysis, types of space indicates gap within writing patterns of the writers. Space can reveal diversification in personality. It is identified into two broad groups as specified below:
Table-I: Types of space classifying character attributes

\begin{tabular}{|c|c|c|c|}
\hline $\begin{array}{l}\text { Sr. } \\
\text { no }\end{array}$ & Type & Personality Traits & Writing Sample \\
\hline 1 & $\begin{array}{l}\text { Wide } \\
\text { Spacing }\end{array}$ & $\begin{array}{l}\text { discrimination, } \\
\text { good taste, } \\
\text { independence, } \\
\text { exclusiveness, } \\
\text { isolation, } \\
\text { loneliness, } \\
\text { snobbery, and } \\
\text { pride. }\end{array}$ & Out, out, buisf canale! \\
\hline 2 & $\begin{array}{l}\text { Narrow } \\
\text { Spacing }\end{array}$ & $\begin{array}{l}\text { warmth, } \\
\text { sympathy, } \\
\text { gregariousness, } \\
\text { obtrusiveness, } \\
\text { poor taste, and } \\
\text { inability to } \\
\text { be alone }\end{array}$ & 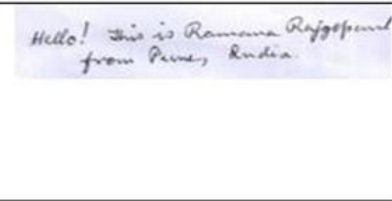 \\
\hline
\end{tabular}

In 2016, Avishek Bal and Rajib Saha [12] proposed discussed about skew normalization procedures.

In 2012, Subhash Panwar and Neeta Nain [13] proposed the amount of space left between one line and the next establishes how well she organizes her life. The method has been evaluated on various styles of handwritten text documents, and it is found that it detects the exact skew angle with more than $98 \%$ accuracy.

In 2018, M. Beketov, K. Lehmann and M. Wittke[19] propositioned quantitative methods inside the robots.

In 2018, Daniel Smyth [21] propositioned a method for predictive analytics using statistics and artificial intelligence to make predictions about switching.

In 2017, L. Bjerknes and A. Vukovic [20] propositioned Perspective on Robo-Advisors and their way of analyzing a questionnaire as input.

\section{RECOMMENDED WORK}

Usually skew is measured to bring the lines to the same base. Space between words are calculated after skew normalization is performed on input document image. According to the review of existing work done [3], [7], [13], [16], there are a number of pre-defined character traits analyzed on the basis of space calculations. Existing techniques [3] only state the classifications theoretically depending on psychological scenarios but are unable to prove their existence experimentally which is tested here.

The recommended plan of action deals with exact classification of characteristics by the explanation of space calculations in handwriting document [11]. This is achieved by comparing the diameter mean of the closed looped characters and the mean word space of the document and then mapping them with the requirements of job profile to analyze switching of job. Performance Analysis through appraisal is an important aspect in this case.

The first step of the work being collection of color handwriting documents to be given as input to the roboadvisor[1]. The given input images are assumed to include only the skews which are considered for removal at the later stage. After applying skew normalization[1] on the document when it becomes free from skew, segmentation is performed on the lines to extract words by projection profile [2] [4]. The space calculations between the words are done and ready to be analyzed. 
Finally, the diameter mean comprising all inner looped letters is found out. Now the value is matched against spacing within words in that document. [10] The detailed methodology taken up for computations of spacing on the rotated image is explained in methodology section and the results are well visible in the findings section.

After all, the behavior traits received from comparison of the space calculated from their samples and the mean of the diameters are matched with the pre-defined ones requirements for choosing a job profile. The comparison of the performance appraisal over the years is the deciding factor for switching of job and selection of the job to be switched to.[21] This can be achieved by a prediction analysis done with artificial intelligence.

\section{METHODOLOGY/ALGORITHM}

\section{A. Algorithm 1}

- Skew Normalization on the document:

This is applied on the document to make it free from positive and negative skews and convert it into a straight line.

Steps:

1. if $(\mathrm{x} 1>\mathrm{x} 2)$

2. \%negative skew

3. $\mathrm{t}=\mathrm{x} 1$;

4. $\mathrm{x} 1=\mathrm{y} 1$;

5. $\mathrm{y} 1=\mathrm{t}$

6. $\mathrm{t}=\mathrm{x} 2$;

7. $\mathrm{x} 2=\mathrm{y} 2$;

8. $\mathrm{y} 2=\mathrm{t}$;

9. $\mathrm{y} 2=\mathrm{y} 1+\mathrm{y} 1-\mathrm{y} 2$;

10. slope $=(\mathrm{y} 2-\mathrm{y} 1) /(\mathrm{x} 2-\mathrm{x} 1)$;

11. angle $=$ atand $($ slope $)$;

12. rot=imrotate(newmatrix,-angle);

13. imshow(rot);

14. $[\mathrm{rr}, \mathrm{cc}]=\operatorname{size}(\mathrm{rot})$;

15. rend=rstart+rr-1;

16. $\operatorname{rotated}($ rstart:rend $, 1: \mathrm{cc},:)=\operatorname{rot}$;

17. rstart=rend +1 ;

18. else

19. \%positive skew

20. $\mathrm{t}=\mathrm{x} 1$;

21. $\mathrm{x} 1=\mathrm{y} 1$;

22. $\mathrm{y} 1=\mathrm{t}$;

23. $\mathrm{t}=\mathrm{x} 2$;

24. $\mathrm{x} 2=\mathrm{y} 2$;

25. $\mathrm{y} 2=\mathrm{t}$;

26. $\mathrm{y} 2=\mathrm{y} 1+\mathrm{y} 1-\mathrm{y} 2$;

27. slope $=(\mathrm{y} 2-\mathrm{y} 1) /(\mathrm{x} 2-\mathrm{x} 1)$;

28. angle $=$ atand (slope);

29. rot=imrotate(newmatrix,angle);

30. $[\mathrm{rr}, \mathrm{cc}]=\operatorname{size}(\mathrm{rot})$;

31. rend=rstart+rr-1;

32. $\operatorname{rotated}($ rstart:rend $, 1: \mathrm{cc},:)=\operatorname{rot}$;

33. rstart=rend +1 ;

34. end

35. end

36. imshow(rotated);

B. Algorithm 2
- Calculation of Spacing between lines on rotated image:

Steps:

1. horpro<- horizontal_projection(rotated);

2. for (each element in horpro)

3. if valuehor $>10000$

4. else

5. line ends;

6 . beginning and ending pixels in "lineskew" matrix

7. End-if

8. lineskew(3)-lineskew(2) indicates space within previous sentence and next sentence and thus it goes on for the whole document.

9. In this way, we compute the gap within sentences while "total space/total linecount" function refers to the mean distance in lines of the document.

Algorithm 2 clearly shows we have calculated the mean line space in rotated image.

\section{Algorithm 3}

- $\quad$ Computing space between words on skewed image: Steps:

1. beg $=1$; position=size_of(lines)

2. while(beg $<=$ position) do

3. newmatrix $=\operatorname{img}(\operatorname{lines}($ beg $): \operatorname{lines}(\operatorname{beg}+1))$

4. verproj<-vertical_projection (newmatrix)

5 . for(each element in verproj)

6. if(valuever $>450$ )

7. $\operatorname{hashm}(\mathrm{i})=\operatorname{hashm}(\mathrm{i}-1)+1$

8. else

9. $\operatorname{hashm}(\mathrm{i})=0$;

10. endif

11. endfor

12. word_extract(newmatrix);

13. wordbeg $=1$;

14. poswords=size_of(words)

15. while(wordbeg $<=$ poswords) do

16.newmatrix_word=img(words(wordbeg):words(wordbe $\mathrm{g}+1))$

17.totalwspace $=$ totalwspace + words $($ wordbeg $)$ words(beg-1)

18. char_extract(newmatrix_word);

Algorithm 3 indicates the calculation of distance within words of a sentence and mean of all those in the skewed document. While words are being extracted, the beginning dot or picture element and the last one are stored in a batch called "Wordskew". For eg, Wordskew(1) and Wordskew(2) indicates beginning and last column dot or picture elements respectively of previous word and the following word. In this way, the calculation of the diameter mean of these spaces are performed. 


\section{Algorithm 4}

- Calculation of space between characters on skewed image:

\section{Steps:}

1. verproj<-verprojtical_projection (newmatrix_word)

2. for(each element in verproj)

3. if(valuever $>450)$

4. hashc $(\mathrm{i})=\operatorname{hashc}(\mathrm{i}-1)+1$;

5. else

6. hashc $(\mathrm{i})=0$;

8. endfor

9. chbeg $=3$;

10. while(beg $<=$ poschar)

11. totalchspace=totalchspace + chars (beg) - chars (beg-1);

12. endwhile

Algorithm 4 indicates the calculation of gap within letters of words and diameter mean of all those in the skewed document. While characters are being extracted, the beginning dot or picture element and the ending one are stored in a batch called "Charskew". An example isCharskew(1) and Charskew(2) depict the beginning as well as last column dots or picture element of the previous and the next character. In this way, the calculation of the diameter mean of these spaces are performed.

\section{E. Algorithm 5}

- Diameter mean calculation of closed looped characters:

Steps:

1. $r g b=i m r e a d(i m g)$;

2. gray_image $=$ convertToGrayScale(img);

3. [centers,radii] $=$ imfindcircles(gray_image, [130], , Object Polarity ${ }^{\text {ee }},{ }^{\text {eedarke }}$, "ensitivity ${ }^{\text {ee }}, 0.9$ );

4. [centersBright,radiiBright $]=$ imfindcircles $(\mathrm{rgb}$,

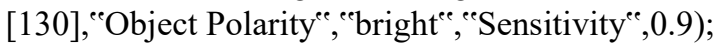

Algorithm 5 uses function imfindcircles() which clearly detects round objects with radius 1 to 30 units. All the bright circular objects are considered as closed loops of letters and are eventually taken into the calculations of diameter mean.

\section{FINDINGS \& RESULTS}

\section{A. Outputs}

The application of recommended plan was over 600 specimen handwritten notes written by diverse writer on various backgrounds. Existing algorithms can convert any type of skew angle to baseline by taking relevant methods of rotation while current recommended technique can compute the distance within words on the skewed image from segmented lines along with it.

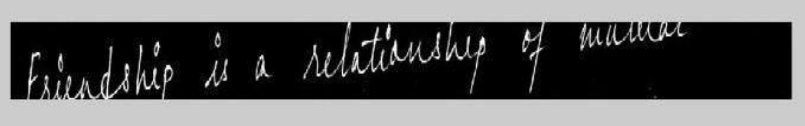

Fig 4. Actual text line from document

In the above Fig. 4, the text line contains negative skew and on application of skew normalization, it became completely proportioned and rotated corresponding to standard line as in Fig. 5. This is followed by segmenting line and word by projection algorithms as in Fig. 6 along
7. endif

with Fig. 7. Experimental sample of all the exercises were well executed in MATLAB on IAM database [1] over 600 text images in a few specimen handwritten notes written by diverse writer on various backgrounds.

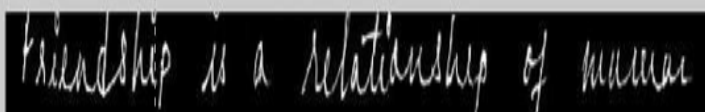

Fig 5: Text line from document after normalization

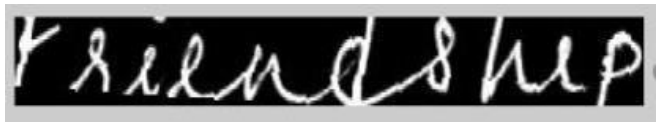

Fig 6: Segmented word

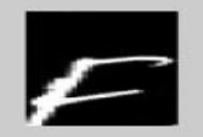

Fig 7: Segmented character

From the different segmented words, the space in between them are calculated in pixels.

\section{B. $\quad$ Figures and Tables}

The significant efficiency of space calculation is shown in Table (II).

Table-II: Space calculation on skew normalized document

\begin{tabular}{|l|l|l|l|}
\hline $\begin{array}{l}\text { Sl. } \\
\text { No }\end{array}$ & $\begin{array}{l}\text { Line Space after } \\
\text { Skew Normalization }\end{array}$ & $\begin{array}{l}\text { Word Space after } \\
\text { Skew Normalization }\end{array}$ & $\begin{array}{l}\text { Character Space } \\
\text { after Skew } \\
\text { Normalization }\end{array}$ \\
\hline 1 & 33.25 & 13.95 & 1.0932 \\
\hline 2 & 11 & 11.73 & 1.0932 \\
\hline 3 & 38.40 & 22.86 & 1.21 \\
\hline 4 & 18.52 & 32.33 & 8.204 \\
\hline 5 & 9.4286 & 11.5625 & 3.7165 \\
\hline 6 & 6.6429 & 6.3333 & 1.7964 \\
\hline 7 & 14.1429 & 27.2581 & 1.1779 \\
\hline 8 & 5.5 & 10.96 & 1.73 \\
\hline 9 & 29.45 & 24.20 & 1.58 \\
\hline 10 & 6.78 & 11.777 & 1.704 \\
\hline 11 & 8.700 & 14.75 & 1.22 \\
\hline 12 & 10.50 & 18.67 & 1.55 \\
\hline 13 & 5.619 & 14.868 & 1.51 \\
\hline 14 & 8.88 & 15.52 & 1.17 \\
\hline 15 & 7 & 4.400 & 1.28 \\
\hline & & & \\
\hline
\end{tabular}

compare it too. Investigaters searched for clues of forgery by first analyzing the pattern texture. Horfmanns writting was cracked. In Hoffmann's basement, forgery books were feund. Investiagters, after 16 months or work came to the conclusion that Hoftmann killed Christenson. The reason that led them to this conclusion was the figured out the ink formula Hoffmann used to forge this letter. Hoffunann killed christenson because he was suspriceus of

Fig 8. Original text document

Published By: Blue Eyes Intelligence Engineering 


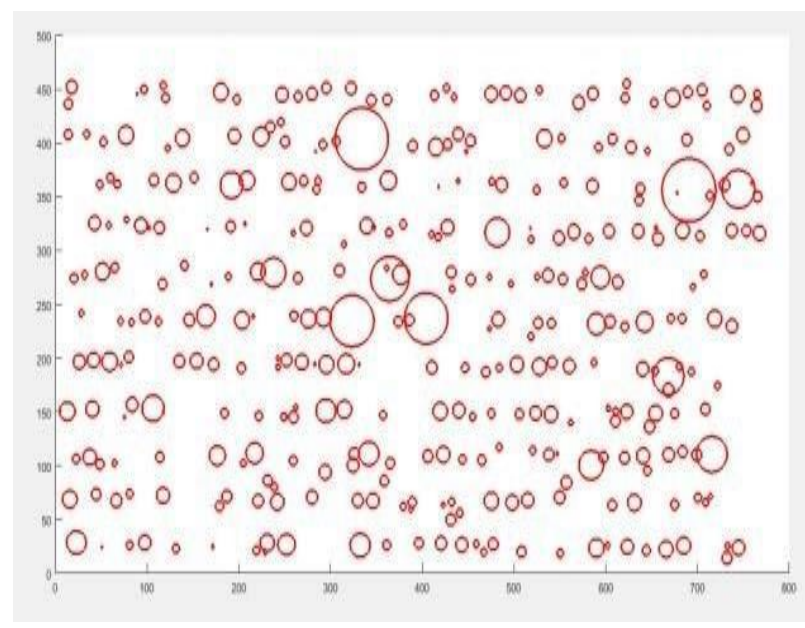

Fig 9. Identified closed loops of the letters of document

Table-III: Character classification based on space calculation

\begin{tabular}{|l|l|l|l|l|}
\hline $\begin{array}{l}\text { Sl. } \\
\text { No }\end{array}$ & $\begin{array}{l}\text { No. of Loops } \\
\text { Detected }\end{array}$ & $\begin{array}{l}\text { Radius } \\
\text { (mean) }\end{array}$ & $\begin{array}{l}\text { Diameter } \\
\text { (mean)* }\end{array}$ & $\begin{array}{l}\text { Character } \\
\text { Analysis }\end{array}$ \\
\hline 1 & 767 & 4.16 & 16.64 & Conventional \\
\hline 2 & 100 & 2.93 & 11.73 & Balanced \\
\hline 3 & 723 & 3.46 & 13.84 & Open-minded \\
\hline 4 & 872 & 5.10 & 20.40 & Open-minded \\
\hline 5 & 521 & 3.21 & 12.84 & Conventional \\
\hline 6 & 484 & 3.17 & 12.68 & Conventional \\
\hline 7 & 560 & 3.22 & 12.88 & Open-minded \\
\hline 8 & 540 & 3.05 & 12.20 & Conventional \\
\hline 9 & 691 & 4.31 & 17.24 & Open-minded \\
\hline 10 & 367 & 2.94 & 11.77 & Balanced \\
\hline 11 & 418 & 2.86 & 11.44 & Open-minded \\
\hline 12 & 449 & 2.50 & 10.00 & Open-minded \\
\hline 13 & 576 & 3.22 & 12.88 & Open-minded \\
\hline 14 & 454 & 3.84 & 7.68 & Open-minded \\
\hline 15 & 100 & 5.15 & 10.30 & Conventional \\
\hline
\end{tabular}

Table (III) states it clearly that recommended technique is efficient for character classification and can work with any

\begin{tabular}{|l|l|}
\hline Conventional & 1. Stereotyping \\
& 2. Judgemental \\
& 3. Restricted \\
& 4. Introvert \\
& 5. Not open to ideas \\
& 6. Pin-pointing shortconing of others \\
& 7. Obsessed with righteousness \\
8. Cannot acceptrejection \\
\hline Open-minded & 1. Open to newideas \\
& 2. Fexible to changes \\
& 3. Extrovert \\
& 4. Live in present \\
& 5. Donot categorizepeople \\
& 6. Handle complex situations \\
& 7. Notjudgemental \\
8. Tumproblemsinto opporturities \\
\hline Balanced & 1. Think out of the box \\
& 2. Socialize with others \\
& 3. Confident \\
& 4. Extrovert \\
& 5. Fexible \\
& 6. Restricted \\
& 7. Realistic \\
8. Active
\end{tabular}

inclusion of skew angle till 3600. Analysis is based on the mathematical study that when double the diameter mean is less than space between words, the person is expected to be broad-minded and vice-versa and if equal, the person is balanced[9]. This recommended plan is $64 \%$ more accurate than the existing techniques.
Table-IV: Traits based on character analysis

\begin{tabular}{|l|l|l|}
\hline \multirow{4}{*}{ Marketing } & Curiosity & Conventional \\
\cline { 2 - 3 } & $\begin{array}{l}\text { Compatible with } \\
\text { others }\end{array}$ & Open-minded \\
\hline \multirow{5}{*}{ HR } & Self-awareness & Balanced \\
\cline { 2 - 3 } & Open to ideas & Open-minded \\
\cline { 2 - 3 } & Agreeableness & Conventional \\
\cline { 2 - 3 } & Think out of the box & Balanced \\
\cline { 2 - 3 } & Extrovert & Open-minded \\
\cline { 2 - 3 } & Aligned to goals & Balanced \\
\cline { 2 - 3 } & Balancing & Balanced \\
\hline & Patience & Conventional \\
\cline { 2 - 3 } & Trustworthy & Conventional \\
\cline { 2 - 3 } & Multi-tasker & Balanced \\
\cline { 2 - 3 } & Ambitious & Conventional \\
\cline { 2 - 3 } & Positive Attitude & Conventional \\
\hline
\end{tabular}

Table (IV) classifies each category of people and their detailed character traits are described.

Table V. Skills required for selection of job profile based on character

\begin{tabular}{|l|l|l|}
\hline $\begin{array}{c}\text { Types of } \\
\begin{array}{c}\text { Specialization in } \\
\text { Business }\end{array}\end{array}$ & \multicolumn{1}{|c|}{$\begin{array}{c}\text { Character Traits } \\
\text { Required } \\
\text { Finance }\end{array}$} & $\begin{array}{c}\text { Character } \\
\text { Available } \\
\text { Matched }\end{array}$ \\
\hline & $\begin{array}{l}\text { Innate Problem } \\
\text { Solver }\end{array}$ & Open-minded \\
\cline { 2 - 3 } & Analytical Skills & Balanced \\
\cline { 2 - 3 } & $\begin{array}{l}\text { Exceptional } \\
\text { Leadership }\end{array}$ & Balanced \\
\cline { 2 - 3 } & $\begin{array}{l}\text { Adaptable } \\
\text { Communication }\end{array}$ & Open-minded \\
\cline { 2 - 3 } & Confidence & Balanced \\
\cline { 2 - 3 } & Self-management & Balanced \\
\hline
\end{tabular}

In Table (V), the skills and personality required for each profile in business are shown. On comparing those features with the already available traits, the type of job profile each one should acquire or take up in business is specified.

Table VI. Performance analysis and switch prediction

\begin{tabular}{|c|c|c|c|c|c|c|}
\hline $\begin{array}{c}\text { Sl. } \\
\text { No }\end{array}$ & $\begin{array}{c}\text { Character } \\
\text { Analysis }\end{array}$ & $\begin{array}{c}\text { Area of } \\
\text { Job }\end{array}$ & $\begin{array}{c}\text { Previous } \\
\text { Appraisal }\end{array}$ & $\begin{array}{c}\text { Current } \\
\text { Appraisal }\end{array}$ & $\begin{array}{c}\text { Switch } \\
\text { Decision }\end{array}$ & $\begin{array}{c}\text { Switch } \\
\text { Area }\end{array}$ \\
\hline 1 & Conventional & Marketing & 4.2 & 3.9 & Yes & HR \\
\hline 2 & Balanced & Finance & 4.3 & 4.5 & No & - \\
\hline 3 & Open-minded & HR & 3.9 & 3.6 & Yes & $\begin{array}{c}\text { Finance/ } \\
\text { Marketing }\end{array}$ \\
\hline 4 & Open-minded & Marketing & 3.9 & 4.2 & No & - \\
\hline 5 & Conventional & Finance & 3.9 & 3.9 & Yes & HR \\
\hline 6 & Conventional & HR & 4.5 & 4.7 & No & - \\
\hline 7 & Open-minded & Finance & 4.4 & 4.6 & No & - \\
\hline 8 & Conventional & Marketing & 4.5 & 4.9 & No & - \\
\hline 9 & Open-minded & Marketing & 4.4 & 4.7 & No & - \\
\hline 10 & Balanced & HR & 4.8 & 5.0 & No & - \\
\hline 11 & Open-minded & Finance & 3.8 & 4.2 & No & - \\
\hline 12 & Open-minded & Finance & 4.1 & 3.7 & Yes & Marketing \\
\hline 13 & Open-minded & Marketing & 4.3 & 4.3 & Yes/No & Finance \\
\hline 14 & Open-minded & HR & 4.0 & 3.8 & Yes & $\begin{array}{c}\text { Finance/ } \\
\text { Marketing }\end{array}$ \\
\hline 15 & Conventional & Marketing & 4.1 & 43 & No & - \\
\hline
\end{tabular}

Published By: 
In Table (VI), the performance analysis of the people selecting these particular job profile is shown. It is seen through predictive analysis that the appraisal performances has degraded in some cases where there can be a possibility of switch over other fields. Now the question lies in which ones to switch. Here artificial intelligence eliminates the same type of profile keeping open the other profiles requiring the same behavior traits.

\section{CONCLUSION}

Plan of action recommended for predicting switching of jobs in business is based on the writer's writing pattern in current instance and performance analysis. Using the recommended plan, 97\% lines were normalized with little error rate and the prediction of switching of jobs based on analysis of character using computation of spacing is performed having $64 \%$ level of efficiency. This technique deals with exact grouping of inner traits and mapping them with the job profile best suited for them. It is very efficient and can work with skew.

The future work can include mapping of more character classifications and with sectors or profile of jobs other than management ones with the recommended plan removing the overlapping loops detected.

\section{ACKNOWLEDGMENT}

The authors are highly obliged to the IBS, Kolkata for providing the opportunity to work on 'Robo-Advisors to Predict Switching of Jobs Using Space in Handwriting Image'. All the authors sincerely express their gratitude to Dr. Ajay Pathak, Director of IBS, Kolkata for supporting and encouraging them to carry out experimentation in the area of innovation of digital trends in business methods.

\section{REFERENCES}

1. S. Nicolas, T. Paquet, L. Heutte, Text Line Segmentation in Handwritten Document Using a Production System, Proceedings of the 9th Int ${ }^{\text {" }} 1$ Workshop on Frontiers in Handwriting Recognition (IWFHR-9 2004), IEEE, 2004.

2. S. Kedar, V. Nair, S. Kulkarni, Personality Identification through Handwriting Analysis, IJARCSSE, 2015.

3. M Sarfraj and Z Rasheed Skew Estimation and Correction of Text using Bounding Box, Fifth IEEE conference on Computer Graphics, Imaging and Visualization, pp. 259-264, 2008.

4. Andria, G.; Savino, M.; Trotta, A.; Application of Wigner-Ville distribution to measurements on transient signals, Instrumentation and Measurement, IEEE Transactions on, vol.43, no.2, pp.187- 193, Apr 1994.

5. Srihari, S.N. and Govindraju , Analysis of textual image using the Hough transform, Machine Vision Applications Vol. 2 141-153,1989.

6. N. Otsu, "A threshold selection method from Gray level histogram", IEEE Transaction on system, Man, Cybernetics, VOL.SMC-9, pp 62-66, January 1979.

7. Champa H N, K R A. Kumar, Automated Human Behavior Prediction through Handwriting Analysis, 2010 First International Conference on Integrated Intelligent Computing,IEEE,978-0-76954152-5/10, 2010
8. Yan Solihin and C.G. Leedham, Noise and Background Removal from Handwriting Images",1997 IEEE.

9. A.Roy, T.K.Bhowmik, S.K.Parui and U.Roy, A Novel Approach to Skew Detection and Character Segmentation for Handwritten Bangla Words, "Proceedings of the Digital Imaging Computing: Techniques and Applications ",IEEE,0-7695- 2467$2 / 05,2005$.

10. U,-V. Marti and H. Bunke, Text Line Segmentation and Word Recognition in a System for General Writer Independent Handwriting Recognition, IEEE,0-76951263-1/01,2001.

11. G. Story, L. O Gorman, D. Fox, L. Schaper and H. Jagadish, The right pages image-based electronic library for alerting and browsing, Computer, vol. 25, no. 9, pp. 17-26, September 1992.

12. A Bal and R. Saha, An Improved Method for Text Segmentation and Skew Normalization of Handwriting Image, Proceedings of the Springer International Conference ICACNI -2016, September 2016.

13. 13. S. Panwar, N. Nain, A Novel Approach of Skew Normalization for Handwritten Text Lines and Words, Eighth International Conference on Signal Image Technology and Internet Based Systems,IEEE,978-0-7695-4911- 8/12,2012 IEEE.

14. J. Das Gupta and B. Chanda, Novel Methods for Slope and Slant Correction of Off-line Handwritten Text Word,2012 Third International Conference on Emerging Applications of Information Technology (EAIT),IEEE,978-1- 4673-1827-3/12/\$31.00,2012.

15. F. Simistira, V. Papavassiliou, T. Stafylakis, Enhancing Handwritten Word Segmentation by Employing Local Spatial Features, 2011 International Conference on Document Analysis and Recognition,IEEE,15205363/11,2011.

16. M. Zimmermann, H. Bunke, Automatic Segmentation of the IAM Off-line Database for Handwritten English Text, IEEE, 1051:465:1/02,2002.

17. V. Papavassiliou, T. Stafylakis, V. Katsouros, and G. Carayannis, Handwritten document image segmentation into text lines and words, Pattern Recognition, vol. 43, Jan. 2010, pp. doi:10.1016/j.patcog.2009.

18. F. Luthy, T. Varga, H. Bunke, Using Hidden Markov Models as a Tool for Handwritten Text Line Segmentation, Ninth International Conference on Document Analysis and Recognition (ICDAR 2007),07695-2822-8/07,2007.

19. M. Beketov, K. Lehmann, M. Wittke, Robo-Advisors: quantitative methods inside the robots, Springer Journal of Asset Management. October 2018.

20. L. Bjerknes, A. Vukovic, Automated Advice: A Portfolio Management Perspective on Robo-Advisors, Norwegian Univerprojsity of Science and Technology, June 2017.

21. D. Smyth, Innovations and trends: How AI is improving predictive analytics, Springer Conference on Predictive Analytics, June 2018. 


\section{AUTHORS PROFILE}

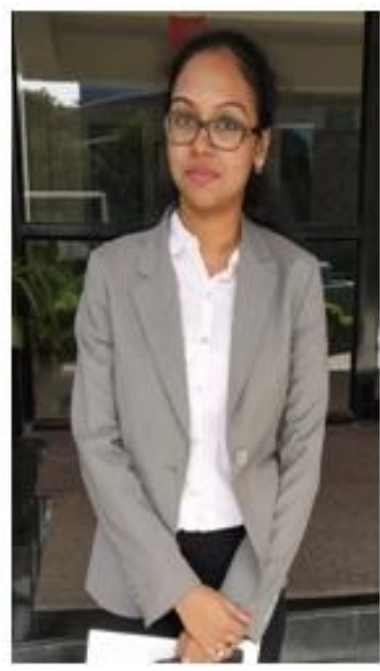

Raised in Kolkata, Ms Sudiksha Chakraborty is currently pursuing her MBA in Finance from IBS Kolkata. Having worked with Tata Consultancy Services for a considerable time, she has several publications in her name. Some of which are- research article on Character Analysis through Handwriting Analysis published in IJRTBT Journal of Malaysia(2019); research work on Determination of Specialization in Business published in IJSIET Journal(2019), her paper on Space in Handwriting Image published in IEEE Digital Library(2016), RICCE(2016), etc. Apart from this, she has worked as an active member of IEI Students' Chapter(Kolkata) and has organized national welfare campaigns like 'I SMOKE'. Being a passionate singer, she has exposed herself to the nation.

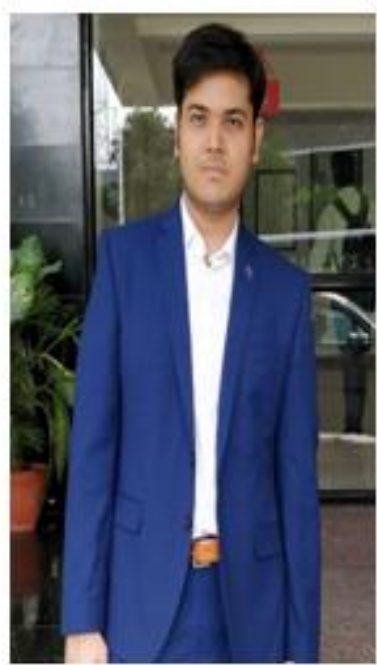

Born and brought up in Kolkata, Mr. Jyoti Majumder is currently pursuing his MBA in Marketing from IBS Kolkata. Having worked with Cognizant Technology Solutions for a considerable time, he has several publications in his name. Some of which are- research article on Character Analysis through Handwriting Analysis published in IJRTBT Journal of Malaysia(2019); research work on Determination of Specialization in Business published in IJSIET Journal(2019), etc. Apart from this, he has worked as an active member of Rotaract Club of Calcutta North East and has a keenness towards Analytics. He has proved himself as an adept painter, crossing the barriers of academics.. 